\title{
A TRAIN-THE-TRAINERS (TtT) PROGRAMME FOR ENGINEERS FOR HOSTING MULTIPARTY INTERNATIONAL CLINICAL TELECONFERENCES
}

\author{
Kuriko Kudo PhD, Tomohiko Moriyama MD, PhD, Shunta Tomimatsu MS, Shintaro Ueda PhD, Shuji \\ Shimizu MD, PhD
}

Telemedicine Development Centre of Asia, International Medical Department, Kyushu University Hospital, Fukuoka, Japan

\begin{abstract}
Background: International clinical teleconferencing connecting hospitals contributes to the standardisation of medical care. Introduction: The perception that participating in international teleconferences is easy while hosting and coordinating them is difficult has limited the expansion of these kinds of programmes. We evaluated the effectiveness of a Train-the-Trainer (TtT) programme on hosting international multiparty teleconferences targeted at hospital engineers. Methods: From 2015 to 2017, 20 engineers and physicians from 17 institutions in 10 countries participated in Kyushu University Hospital's TtT programme. Hands-on training and hosting a Training Report Conference (TRC) were conducted. The impact of the programme was assessed using questionnaires about the participants' confidence, perception of barriers, and teleconference activity before and one year after the training period. Results: The mean training period was 16.7 days (median, 19 days). Twelve TRCs were hosted by trainees connecting 56 institutions in 11 countries. All participants gave positive evaluations of the overall programme, 19 (95\%) "very good" and 1 (5\%) "good", and the trainers $9(90 \%)$ "very good" and 1 (10\%) "good"). Following the TtT programme, the mean number of trainee-hosted events increased significantly $(0.8$ to $1.3, \mathrm{p}<0.001)$, and more respondents $(12 / 17,71 \%)$ reported barriers to hosting a programme than participating in one $(5 / 17,29 \%, \mathrm{p}<0.001)$. Trainee confidence in both hosting and participating in international teleconferences was significantly higher after TtT. Conclusion: There are more barriers to hosting than participating in international clinical teleconferences. This TtT programmes for engineers could contribute to more active hosting engagement.
\end{abstract}

Keywords: telemedicine; distant learning; train-the-trainer; videoconference; international; multiparty

Kudo K, et al. JISfTeH 2019;7:e16(1-8).

DOI: https://doi.org/10.29086/JISfTeH.7.e16

Copyright:@ The Authors 2018

Open access, published under Creative Commons Attribution 4.0 BY International Licence

\section{Introduction}

The quality of health and medical care varies by country. The clinical situation of gastric cancer is a striking example. ${ }^{1,2}$ Although the mortality rate of gastric cancer is less than half of the incidence rate in Japan, the rates of mortality and incidence of gastric cancer in other countries are almost equal. International clinical teleconferencing that features live demonstrations and connects multiple hospitals over the Internet has contributed to the standardisation of medical techniques and knowledge. ${ }^{3,4}$ Through such teleconferencing, gastroenterologists working in areas where there is a high risk of gastric cancer are able to learn advanced endoscopic techniques directly from Japanese gastroenterologists. In addition, international clinical teleconferencing offers a safe and effective learning environment for large numbers of medical staff, particularly during outbreaks of rare infectious diseases such as Zika virus infection and Ebola haemorrhagic fever. Many doctors in low-prevalence areas can learn from the experiences of the few in high-prevalence areas. ${ }^{5,6}$

The worldwide adoption of full-scale telemedicine is limited by the availability of dedicated technical support staff. $^{7}$ Although participation of healthcare workers in these kinds of international teleconferences is reasonably achievable because of the recent development of information and communication technologies, the perceived difficulties associated with hosting these programmes remains a problem. ${ }^{8}$ The differences in technical engineer requirements and duties for the "host" and "participant" parties involved in an international clinical teleconference are shown in Figure 1. At the participant side, on-site engineers are mainly needed to respond to requests initiated by the host. Hosts, however, require a chief engineer to coordinate all technical matters, such as checking the network, videoconference (VC) and audio-visual systems, and aiding troubleshooting by the onsite engineers. The chief engineer must also take into consideration the time zone and network system differences 


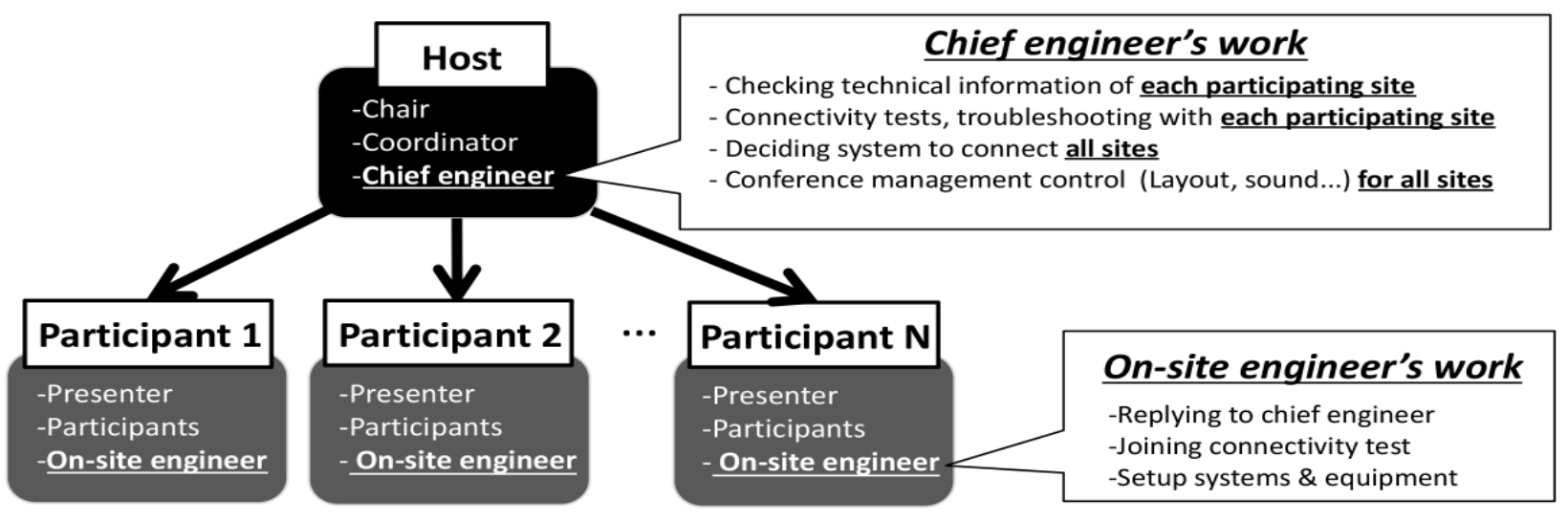

Figure 1. Organisation of technical engineer requirements for hosting vs. participating in an international clinical teleconference. among participating institutions. Although training programmes for remote medical education have been implemented, there are very few reports on hosting international multiparty teleconferences. ${ }^{9,10}$

Our hospital has conducted international clinical teleconferences since 2002, ${ }^{11}$ and by the end of 2015, 346 hospitals and universities in 51 nations/regions had participated. Over $80 \%$ of our programmes were multiparty (more than two sites), and over half of the programmes had more than four participating sites, with about $20 \%$ of the programmes having more than 10 participating sites. ${ }^{8} \mathrm{We}$ developed an engineering training programme to assist with the smooth operation of telemedicine through international clinical teleconferences that has been implemented since 2015. The programme is based on a Train-the-Trainer (TtT) model, which delivers efficient training and results in selfsustaining activity. ${ }^{12-14}$ The relationship between "chief engineer" and "on-site engineers" is similar to that between "trainer" and "trainee". A "chief engineer" will guide all "onsite engineers" of connecting institutions in setup of $\mathrm{VC}$ systems and transmission of medical contents, and give hands-on training during connectivity tests. In this study, we analysed the effectiveness of our TtT programme in terms of participant confidence in technical support skills and activated support of international clinical teleconferencing.

\section{Methods}

The targets of this survey were all trainees in the $\mathrm{TtT}$ programme between July 2015 and February 2017. During this period, TtT programmes were held six times with 20 participants from 17 institutions in 10 foreign countries. The training periods were organised to include multiple individuals, and ultimately adjusted to span between 2 and 5 weeks to accommodate the participants' schedules.

The training programme was designed by the Telemedicine Development Centre of Asia (TEMDEC) of Kyushu University Hospital. The aim of this programme was to increase the participants' confidence in telemedicine by gaining skills and knowledge in the following subject areas:

1. Workflow of all staff required to set up an international clinical teleconference

2. Quality level of audio-visual transmission required for telemedicine

3. VC systems

4. Technical preparation

5. Troubleshooting.

The contents of the TtT programme were divided into two, hands-on training on VC technical matters and hosting a pilot programme (Table 1). Trainees independently carried out installation, set-up and control of H.323 and Vidyo (Vidyo ${ }^{\mathrm{TM}}$, Hackensack, NJ, US) ${ }^{16,17}$ They were taught how to share medical content with good image and sound quality, and manage a multipoint control unit (MCU) for multiparty connection. At the end of the programme, trainees were assigned to host their own teleconference entitled "Training Report Conference" (TRC), connecting hospitals and universities in their home countries and other countries depending on the conference programme. (Figure 2)

In the TRCs, the trainees acted as the chief engineer, and presented and discussed their achievements during the training period. Trainees designed their respective TRCs in consultation with their colleagues, physicians and the staff of Kyushu University Hospital, and announced the conference programmes by email and posts on the website of TEMDEC to promote participation. The technical coordination was done as follows. Firstly, trainees contact participants and onsite engineers in all connecting institutions about the VC experience and local equipment. If all remote sites were equipped with H.323 software or hardware codec connected to the Internet, trainees chose H.323 for the whole connection using MCU. If none of the remote sites were equipped with a VC system, trainees chose Vidyo and on-site engineers installed Vidyo on their computer connected to the Internet. If some of remote sites were equipped with H.323 software or hardware codec, the trainees chose to use VidyoGateway 
Table 1. Outline of the Train-the-Trainer (TtT) programme content.

\begin{tabular}{|c|c|}
\hline \multicolumn{2}{|c|}{ Hands-on training on VC techniques } \\
\hline $\begin{array}{l}\text { General } \\
\text { Guide }\end{array}$ & $\begin{array}{l}\text { - Orientation } \\
\text { - Sharing event schedule }\end{array}$ \\
\hline H.323 & $\begin{array}{l}\text { - Point to point / multipoint connection } \\
\text { - Sharing medical content } \\
\text { - Conference management }\end{array}$ \\
\hline Vidyo & $\begin{array}{l}\text { - Participation } \\
\text { - Sharing medical content } \\
\text { - Recording and live streaming } \\
\text { - H.323 gateway connection } \\
\text { - Conference management }\end{array}$ \\
\hline $\begin{array}{l}\text { Additional } \\
\text { tools }\end{array}$ & $\begin{array}{l}\text { - Annotation } \\
\text { - Online chat tool }\end{array}$ \\
\hline Tours & $\begin{array}{l}\text { - Operation room } \\
\text { - Endoscopy simulator system } \\
\text { - Hospital information system }\end{array}$ \\
\hline \multicolumn{2}{|c|}{ Hosting a Pilot Programme (TRC) } \\
\hline Week 1 & $\begin{array}{l}\text { - Workflow for hosting an international clinical } \\
\text { VC } \\
\text { - Drafting a conference programme } \\
\text { - Taking tests and attending pre-organised } \\
\text { conferences }\end{array}$ \\
\hline Week 2 & $\begin{array}{l}\text { - Drafting the conference programme and } \\
\text { mailing list } \\
\text { - Contacting the engineers and physicians in all } \\
\text { participating institutions regarding the } \\
\text { technical situation at each institution } \\
\text { - Selecting a VC system to accommodate the } \\
\text { technical situations of all participating } \\
\text { institutions } \\
\text { - Technical announcement to all on-site } \\
\text { engineers } \\
\text { - Connectivity test and troubleshooting with all } \\
\text { on-site engineers }\end{array}$ \\
\hline Week 3 & $\begin{array}{l}\text { - Programme announcement to the mailing list } \\
\text { and website } \\
\text { - Organising a rehearsal with all institutions } \\
\text { - Gathering all presentation files for backup }\end{array}$ \\
\hline Week 4 & $\begin{array}{l}\text { - Delivering the TRC } \\
\text { - Sharing presentations } \\
\text { - Operating a multipoint control unit } \\
\text { - Communication with remote-site engineers } \\
\text { during the TRC } \\
\text { - Presentation on the achievements of the TtT } \\
\text { programme }\end{array}$ \\
\hline
\end{tabular}

which enables the interconnection of H.323 and Vidyo (H.264 and H.265-SVC).

Questionnaires were sent by email before and after the training period to evaluate the TtT programme. Three types of questions were formulated: 1) Pre/Post confidence; 2) Training programme; 3) Follow-up. Section 1) was a selfevaluation of the trainees' confidence on items when engineers support participating/hosting an international telemedicine conference before and after $\mathrm{TtT}$ programme, with the following answer options: 1 = "Definitely No", 2 =

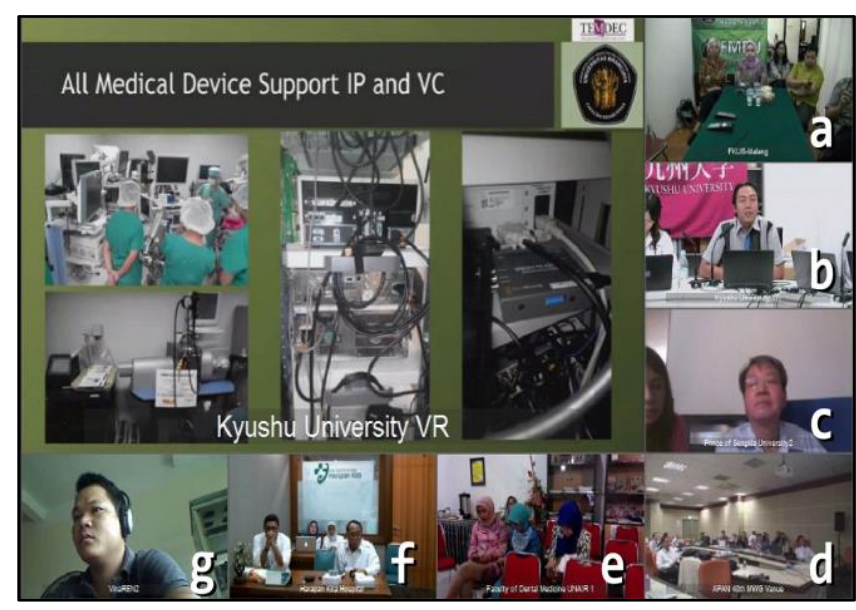

Figure 2. Representative photos of the trainee-hosted Training Report Conferences connecting hospitals and universities within Indonesia, Malaysia, Thailand, Vietnam and Japan: (a) Brawijaya University, Indonesia; (b) Kyushu University Hospital, Japan; (c) Prince of Songkla University, Thailand; (d) University of Malaya, Malaysia; (e) Airlangga University, Indonesia; (f) Harapan Kita Children and Mother Hospital, Indonesia; and (g) NASATI Office, Vietnam.

"Probably No", 3 = "Not Sure", 4 = "Probably Yes", and 5 = "Definitely Yes". In section 2), trainees were asked to evaluate different aspects of the TtT programme as "Very good", "Good", "Poor", or "Very Poor". Section 3) was a yes/no question regarding the barrier(s) to participating in and/or hosting future programmes. If respondents answered "yes", they were asked about the kinds of barriers and supplied with multiple answer options.

The number of programmes carried out by the trainees for the period from one year before the training to one year after the training was investigated using an international telemedicine conference management database system. ${ }^{17}$ For statistical analyses, we performed the Chi-squared and Spearman's rank correlation tests using JMP Pro (ver. 13.0.0) and Microsoft Excel 2016, with statistical significance set at $\mathrm{p}<0.05$.

\section{Results}

The characteristics of the participants, all of whom were working at key institutions such as a core hospital or university, or an institution of research and education network, in each country are shown in Table 2.

The training, trainees experience and work support are shown in Table 2 and the the number of trainees per session, their experience and work support, in Table 3.

Programme evaluation

The positive evaluation of the TtT programme overall [19/20 (95\%) "very good" and 1/20 (5\%) "good"], and the trainer [9/10 (90\%) "very good" and 1/10 (10\%) "good"] is 
Table 2.Characteristics of the Train-the-Trainer programme participants $(\mathrm{N}=20)$. ( $\mathrm{VC}=$ videoconference $)$

\begin{tabular}{|l|r|}
\hline Country & $4(20 \%)$ \\
\hline Indonesia & $3(15 \%)$ \\
\hline Malaysia & $3(15 \%)$ \\
\hline Vietnam & $3(15 \%)$ \\
\hline Mexico & $2(10 \%)$ \\
\hline Philippines & $1(5 \%)$ each \\
\hline Thailand, Brazil, Chile, Costa Rica, and Nepal \\
\hline Gender & $18(90 \%)$ \\
\hline Male & $2(10 \%)$ \\
\hline Female & $1(5 \%)$ \\
\hline Age (years) & $11(55 \%)$ \\
\hline $20-29$ & $6(30 \%)$ \\
\hline $30-39$ & $2(10 \%)$ \\
\hline $40-49$ & $18(90 \%)$ \\
\hline $50-59$ & $2(10 \%)$ \\
\hline Occupation & $11(55 \%)$ \\
\hline Information Technology engineer & $7(35 \%)$ \\
\hline Physician & $2(10 \%)$ \\
\hline Affiliation
\end{tabular}

Table 3. The training, experience and local support of trainees.

\begin{tabular}{|c|c|}
\hline \multicolumn{2}{|l|}{ Training Term } \\
\hline First (July-August, 2015) & $6(30 \%)$ \\
\hline Second (October-December, 2015) & $3(15 \%)$ \\
\hline Third (February-March, 2016) & $1(5 \%)$ \\
\hline Fourth (July-August, 2016) & $3(15 \%)$ \\
\hline Fifth (November, 2016) & $2(10 \%)$ \\
\hline Sixth (January-February, 2017) & $5(25 \%)$ \\
\hline \multicolumn{2}{|l|}{ Training Period } \\
\hline 4-5 weeks & $13(65 \%)$ \\
\hline 3 weeks & $3(15 \%)$ \\
\hline 2 weeks & $4(20 \%)$ \\
\hline \multicolumn{2}{|c|}{ Past Experience Participating in a Clinical VC } \\
\hline No experience & $1(5 \%)$ \\
\hline Some but not enough experience & $13(65 \%)$ \\
\hline Enough experience & $3(15 \%)$ \\
\hline No answer & $3(15 \%)$ \\
\hline \multicolumn{2}{|c|}{ Past Experience Hosting a Clinical VC } \\
\hline No experience & $7(35 \%)$ \\
\hline Some but not enough experience & $6(30 \%)$ \\
\hline Enough experience & $4(20 \%)$ \\
\hline No answer & $3(15 \%)$ \\
\hline \multicolumn{2}{|c|}{$\begin{array}{l}\text { To What Extent Does Participants' Job Support } \\
\text { Telemedicine }\end{array}$} \\
\hline No support at all & $0(0 \%)$ \\
\hline Little support & $4(20 \%)$ \\
\hline Partial support & $7(35 \%)$ \\
\hline Full support & $6(30 \%)$ \\
\hline No answer & $3(15 \%)$ \\
\hline \multicolumn{2}{|c|}{$\begin{array}{l}\text { Number of Staff Supporting Telemedicine in Participants' } \\
\text { Institution }\end{array}$} \\
\hline $1-2$ & $13(65 \%)$ \\
\hline $3-4$ & $3(15 \%)$ \\
\hline $5-10$ & $1(5 \%)$ \\
\hline No answer & $3(15 \%)$ \\
\hline
\end{tabular}

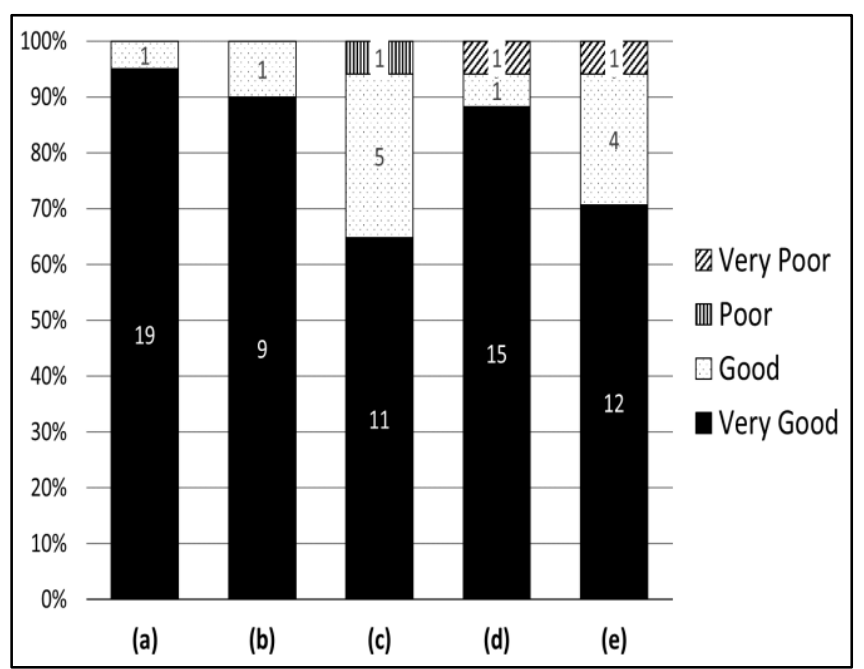

Figure 3. Trainee respondents' evaluation of different aspects of the Train-the-Trainer programme: (a) programme overall; (b) trainer; (c) H.323 hands-on; (d) Vidyo hands-on; and (e) hosting a pilot programme (Training Report Conference).

shown in figure 3 . There were 10 non-respondents who were excluded. Although 16/17 (94\%) of the respondents answered "very good" or "good" regarding each item in the training programme, one respondent $1 / 17$ (6\%) described the H.323 hands-on item as "poor" and both the Vidyo hands-on and Hosting a Pilot Programme items as "very poor". The trainee who gave the "poor" and "very poor" answers was the first participant in the TtT programme, and had participated alone for 3 weeks before another five participants joined.

Training report conferences

Twelve conferences were hosted connecting 56 institutions in 11 countries in total. (Table 4)

Regarding the institutional location, the greatest number of participating sites were from the Philippines (seven sites), followed by Vietnam (six sites), Malaysia (four sites),

Table 4. Details of 12 training report conferences.

\begin{tabular}{|l|c|}
\hline Number of Connecting Institutions \\
\hline$>4$ sites & $6(50 \%)$ \\
\hline $3-4$ sites & $5(42 \%)$ \\
\hline 2 sites & $1(8 \%)$ \\
\hline Number of connecting Countries \\
\hline 2 countries & $8(67 \%)$ \\
\hline $3-4$ countries & $3(25 \%)$ \\
\hline 5 countries & $1(8 \%)$ \\
\hline Participating Institutions by Country \\
\hline $\begin{array}{l}\text { Philippines (7), Vietnam (6), Malaysia (4). Indonesia (4), Costa } \\
\text { Rica (3) }\end{array}$ \\
\hline VC System & $3(25 \%)$ \\
\hline Vidyo & $1(8 \%)$ \\
\hline H.323 & $7(58 \%)$ \\
\hline Both & $2(17 \%)$ \\
\hline Live streaming & $12(83 \%)$ \\
\hline Yes & \\
\hline No &
\end{tabular}


Indonesia (four sites) and Costa Rica (three sites). Five institutions in two countries were newly connected to our hospital: San Juan de Dios Hospital (Costa Rica), Gastro Clinica (Costa Rica), Baguio General Hospital (Philippines), University of Cebu Medical Centre (Philippines) and Davao Doctors Hospital (Philippines). Nearly all 19/20 (95\%) of the participants were able to connect their own institution to their own TRC, with the exception of one trainee whose institution lacked human resource of on-site engineer. Eight of the 12 conferences $(67 \%)$ were conducted by a single trainee, two $(17 \%)$ were conducted by two trainees, one $(8 \%)$ was conducted by three trainees, and one (8\%) was conducted by five trainees.

\section{Confidence in technical support for international clinical} teleconferencing

The participants' self-assessment of confidence in offering technical support for international clinical teleconferencing before and after the training is shown in Table 5. The majority of respondents answered "Probably Yes" and "Definitely Yes" to feeling confident about both participating and hosting (score range, 4.2-4.9) after the TtT programme; all items were significantly higher post training.

Follow-up evaluation

The number of hosting programmes that were delivered by the trainees 1 year before the TtT significantly increased in the year following the $\mathrm{TtT}$ programme $(0.8 \pm 4.1$ to $1.3 \pm$ $6.0, \mathrm{p}<0.001)$. The number of programmes in which the trainees participated also increased, but the difference was not significant $(2.6 \pm 9.7$ to $4.1 \pm 7.7, \mathrm{p}=0.21)$.

The respondents' answers to questions regarding barriers to participating in and/or hosting future programmes are shown in Figure 4. More respondents $12 / 17(79 \%)$ had barriers to hosting than participating 5/17 $(29 \%)$, ( $\mathrm{p}<0.001)$. The barriers they selected are shown in Table 6 .

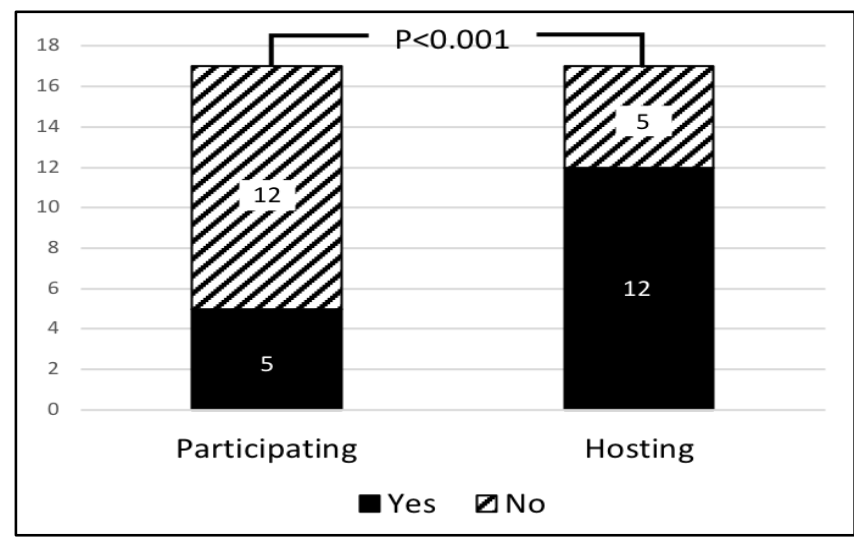

Figure 4. Number of trainee respondents who cited barrier(s) to participating in and/or hosting future international clinical teleconference programmes after attending the Train-theTrainer programme $(\mathrm{N}=17)$.

Table 6. Barriers to hosting future telemedicine programmes.

\begin{tabular}{|l|c|}
\hline Barriers & $\mathbf{n}=$ \\
\hline Lack of equipment & $10(23 \%)$ \\
\hline Shortage of dedicated staff & $6(14 \%)$ \\
\hline Shortage of funding & $6(14 \%)$ \\
\hline Not understanding the supervisor & $4(9 \%)$ \\
\hline Inconsistent with the policy of the faculty & $4(9 \%)$ \\
\hline Time limitations & $3(7 \%)$ \\
\hline English communication & $3(7 \%)$ \\
\hline Time zone differences & $2(4 \%)$ \\
\hline Low bandwidth & $2(4 \%)$ \\
\hline Others & $4(9 \%)$ \\
\hline
\end{tabular}

The most common barrier cited was "lack of equipment" $10 / 44(23 \%)$, followed by "shortage of dedicated staff" and "shortage of funding" $6 / 44$ (14\%) each.

Table 5. Comparison of pre-training and post-training ratings of confidence in offering technical support of an international clinical teleconference $(\mathrm{N}=17)$.

\begin{tabular}{|l|c|c|c|}
\hline \multicolumn{1}{|c|}{ Survey Item } & $\begin{array}{c}\text { Pre TtT } \\
\text { Mean (SD) }\end{array}$ & $\begin{array}{c}\text { Post TtT } \\
\text { Mean (SD) }\end{array}$ & P \\
\hline Confidence in technical support as a participant & $3.2(1.8)$ & $4.5(0.9)$ & $<0.001$ \\
\hline Workflow as a local engineer & $3.1(2.4)$ & $4.9(0.1)$ & $<0.01$ \\
\hline Operating a VC endpoint system & $3.5(1.9)$ & $4.8(0.3)$ & 0.001 \\
\hline Operating audio equipment & $3.4(1.9)$ & $4.7(0.2)$ & $<0.001$ \\
\hline Operating visual equipment & $3.5(2.4)$ & $4.5(1.1)$ & $<0.01$ \\
\hline Operating the network & $3.0(2.2)$ & $4.5(1.1)$ & $<0.001$ \\
\hline Sharing medical content & $2.9(1.9)$ & $4.5(0.5)$ & $<0.001$ \\
\hline Troubleshooting skills & & \multicolumn{2}{|c|}{} \\
\hline Confidence in technical support as a host & $2.8(1.8)$ & $4.6(0.5)$ & $<0.001$ \\
\hline Workflow as the chief engineer & $2.9(1.8)$ & $4.4(0.7)$ & $<0.001$ \\
\hline Selecting a system & $2.9(2.6)$ & $4.6(0.5)$ & $<0.001$ \\
\hline Required quality level for telemedicine & $2.8(2.8)$ & $4.2(0.7)$ & $<0.001$ \\
\hline Operating a large multiparty conference & $2.8(1.8)$ & $4.6(0.5)$ & $<0.001$ \\
\hline Workflow as the chief engineer & \multicolumn{2}{|c|}{} \\
\hline
\end{tabular}

TtT, train the trainer programme; SD, standard deviation. Response scale: 1 = Definitely No, $2=$ Probably No, $3=$ Not Sure, $4=$ Probably, $5=$ Yes. 


\section{Discussion}

There is a common perception among both IT support staff and healthcare workers/physicians that hosting an international multiparty clinical teleconference is more difficult than participating in one. Reasons for this include a lack of equipment required to enable connection of multiple international participating sites and a shortage of dedicated staff who can coordinate between international institutions. In this $\mathrm{TtT}$ programme, trainees were given an opportunity to host an actual conference termed a TRC and invite multiple hospitals from their own countries to attend using the technical infrastructure of TEMDEC. Ultimately, all participants were able to deliver their TRC, connecting 56 institutions in 11 countries in total.

The questionnaire results indicated that this $\mathrm{TtT}$ was a useful tool to support hosting an international clinical teleconference. The trainees' confidence in their technical support skills was significantly higher after the TtT programme on hosting. All participants gave positive evaluations of the overall programme 19/20 (95\%) "very good" and 1/20 (5\%) "good", and the trainers 9/10 (90\%) "very good" and 1/10 (10\%) "good". Furthermore, the mean number of hosting events was significantly increased in the year following the $\mathrm{TtT}$ programme $(0.8$ to $1.3, \mathrm{p}<0.001)$. In the Philippines, a surgery group established the Telemedicine Network in Philippines (TNP) in May 2016, and started hosting teleconferences on minimally invasive surgery that connected hospitals in the Philippines, Thailand, Vietnam and Japan every 3 months. ${ }^{18}$ Two TtT graduates stepped into the role of chief engineer of telemedicine programmes at their respective institutions. In one case, a $\mathrm{TtT}$ participant from Indonesia took charge of a pan-Indonesian endoscopy teleconference that began in October 2016 and has been held monthly since then, connecting 13 national university hospitals in Indonesia and Kyushu University Hospital. In Mexico, a remote endoscopy lecture with Japan has been initiated every 3 months since shortly after the participants from Mexico finished the TtT programme.

Shortages in equipment, dedicated staff, and funding were the main barriers to hosting, which requires a large infrastructure that can connect multiple international institutions, such as MCUs or VC servers with stable network connections with all participating institutions. However, the institutions of many of the trainees were lacking in such infrastructure. Furthermore, in many cases, the VC systems in hospitals were designed for a fixed number of members, networks and endpoints because of network security and ease of maintenance, making it difficult to connect to outside institutions. Updating the skills and knowledge base of technical engineers could be one part of the solution to this widespread challenge because graduates of our TtT programme went on to host more clinical teleconferences even with limitations in network infrastructure.
We carefully considered the feedback on the detailed programme, which was evaluated negatively by one individual. Given that he was the first participant, and for a time the only participant, of the programme, it is possible that the orientation and content explanations were insufficient. As we gained experience conducting the $\mathrm{TtT}$ programme, the delivery of the programmes became smoother. Although improvements based on feedback are important, we recognise that the pre-programme preparations could have been stronger.

There were also methodological limitations to this study. Because the training period and timing of delivery were not fixed, the programme was not unified among the participants. The trainees were small in number and biased by having been invited to participate in the training rather than selected randomly. The results might have been more objective if the participants had been scouted from a larger number of regions and countries. However, to achieve the expansion of teleconference activity domestically, it was important that employees of the key hospitals in each country be involved; therefore, such biases were unavoidable. Secondly, the questionnaire was too simple to evaluate the $\mathrm{TtT}$ programme accurately. Additional questions would have allowed us to evaluate how this programme affected the participants' skills, knowledge and motivation for engineering international clinical teleconferences. However, because all of the trainees gave positive evaluations of the TtT programme overall and its trainers, the usability of this $\mathrm{TtT}$ programme is assured.

Recent innovations in technology allow anyone to use mobile phones, tablets or SMS for accessing to telemedicine without special helps of technician. ${ }^{19-22}$ Stolyar et al introduced the implementation of an university curriculum for medical students regarding telemedicine technologies and practical skills on VC in their article. ${ }^{23}$ In future, more physicians will be able to organise international teleconference by themselves. However, the sharing of highquality medical images by audio-visual transmission across multiple network units of countries, regions and facilities, still requires cooperation between the on-site engineers and administrators in charge of these units. ${ }^{24}$ This programme can contribute to educating the engineers who support hosting of international clinical teleconferences that connect institutions throughout the world. To expand teleconferencing internationally, this type of technical training should be implemented across more hospitals worldwide. 


\section{Corresponding author: \\ Kuriko Kudo}

Telemedicine Development Center of Asia

Kyushu University Hospital

3-1-1 Maidashi, Higashi-ku

Fukuoka 812-8582, Japan

Phone: +81-92-642-5014, Fax: +81-92-642-5983

E-mail: kuricom@tem.med.kyushu-u.ac.jp

Conflict of interest. The authors declare no conflicts of interest.

Acknowledgments. This training programme was supported by the TEIN4 project and the European Commission. This work was supported by JSPS Core-to-Core Programme, B. Asia-Africa Science Platforms, and KAKENHI (grant numbers 15K08556 and 16H02773). We thank Michelle Kahmeyer-Gabbe, PhD, from Edanz Group (www.edanz.com/ac) for editing a draft of this manuscript.

\section{References}

1. Parkin DM. Global cancer statistics in the year 2000. Lancet Onco 2001;2(9):533-543. DOI: https://doi.org/10.1016/S1470-2045(01)00486-7.

2. Yao K, Uedo N, Muto M, et al. Development of an elearning system for the endoscopic diagnosis of early gastric cancer: an international multicenter randomized controlled trial. EBioMedicine 2016;9:140-147. DOI: https://doi.org/10.1016/j.ebiom.2016.05.016.

3. Hoxha Z, Osmani K, Mora F, et al. The Contribution of the telemedicine programme of Kosova on elearning and continuous medical education: the outcomes of the first decade. J Int Soc Telemed eHealth 2013;3:93-97. Available at: http://journals.ukzn.ac.za/index.php/jisfteh/article/view 150 accessed 30 December 2018.

4. Numanoglu A. Using telemedicine to teach paediatric surgery in resource-limited countries. Pediatr Surg Int 2017;33(4):471-474. DOI: 10.1007/s00383-016-40516.

5. Davis D. Continuing medical education. Global health, global learning. BMJ 1998;316(7128):385-389. DOI: https://doi.org/10.1136/bmj.316.7128.385.

6. Moreika A, Raul A-C, Alberto M, Jose C. Enhancing collaborative case diagnoses through unified medical language system-based diambiguation: a case study of the Zika virus. Telemed J E Heal 2016;23(7):608-614. DOI: $10.1089 / \mathrm{tmj} .2016 .0203$.

7. Scott Kruse C, Karem P, Shifflett K, et al. Evaluating barriers to adopting telemedicine worldwide: A systematic review. J Telemed Telecare 2018;24(1):412. DOI: 10.1177/1357633X16674087.

8. Kudo K, Tomimatsu S, Houkabe Y, et al. Five-year technological changes of distant medical education in
Asia. J Int Soc Telemed eHealth 2017(5):e10.

Available at:

http://journals.ukzn.ac.za/index.php/jisfteh/article/view /317 accessed 30 December 2018.

9. Santos A de F dos, Alves HJJ, Nogueira JT, Torres RM, Melo MD. Telehealth distance education course in Latin America: analysis of an experience involving 15 countries. Telemed J E Heal 2014;20(8):736-741. DOI: 10.1089/tmj.2013.0291

10. Krupinski EA, Weinstein RS. Telemedicine in an academic center-The Arizona Telemedicine Programme. Telemed J E Health 2013;19(5):349-356. DOI:10.1089/tmj.2012.0285.

11. Shimizu S, Nakashima N, Okamura K, et al. International transmission of uncompressed endoscopic surgery images via superfast broadband Internet connections. Surg Endosc 2006;20(1):167170. DOI: https://doiorg.ukzn.idm.oclc.org/10.1007/s00464-005-0282-7..

12. Assemi M, Mutha S, Hudmon KS. Evaluation of a train-the-trainer programme for cultural competence. Am J PharmEduc 2007;71(6):110. 2007. PMID: 19503694

13. Stratos GA, Katz S, Bergen MR, Hallenbeck J. Faculty development in end-of-life care: evaluation of a national train-the-trainer programme. Acad Med 2006;81:1000-1007. DOI: 10.1097/01.ACM.0000242475.41549.66.

14. Lee SWH, Mak VSL. Train-the-trainer programme on cardiovascular health for community pharmacists in Malaysia. Int J Clin Pharm 2017;39(6):1166-1170. DOI: $10.1007 / \mathrm{s} 11096-017-0540-5$.

15. Minh CD, Shimizu S, Antoku Y, et al. Emerging technologies for telemedicine. Korean J Radiol 2012;13(Suppl 1):S21-30. DOI: 10.3348/kjr.2012.13.S1.S21.

16. Fatehi F, Armfield R N, Dimitrijevic M, Gray C L. Technical aspects of clinical videoconferencing: a large scale review of the literature. J Telemed Telecare 2015;21(3):160-166. DOI: $10.1177 / 1357633 X 15571999$.

17. Telemedicine Development Center of Asia, About Med-hok. Available at: http://www.temdec.med.kyushuu.ac.jp/medhok_min/about_00outline.html accessed 30 December 2018.

18. Panganiban KM, Jeffrey D. The first telemedicine network of the Philippines "Beyond Borders." Surg Endosc 2017; 31(Suppl 1):68. DOI: https://doi.org/10.1007/s00464-017-5448-6.

19. Zhang K, Liu W-L-L, Locatis C, Ackerman M. Mobile videoconferencing apps for telemedicine. Telemed $J E$ Health 2016;22(1):56-62. 2016. DOI: https://www.liebertpub.com/doi/10.1089/tmj.2015.002 7. 
20. Samelli AG, Rabelo CM, Sanches SGG, Aquino CP, Gonzaga D. Tablet-based hearing screening test. Telemed J E Health 2017;23(9):747-752. DOI: 10.1089/tmj.2016.0253.

21. Walker TWM, Chadha A, Rodgers W, Mills C, Ayliffe P. Electronic follow-up of developing world cleft patients: a digital dream? Telemed $J$ E Health 2017;23(10):847-851. DOI: 10.1089/tmj.2017.0012.

22. Johnston MJ, King D, Arora S, et al. Smartphones let surgeons know WhatsApp: An analysis of communication in emergency surgical teams. Am J Surg 2015;209(1):45-51.DOI: http://dx.doi.org/10.1016/j.amjsurg.2014.08.030.

23. Stolyar V, Lukianova E, Amcheslavskaya M, et al. Modern Approach to the study of telemedicine technologies in the Medical Institute. J Int Soc Telemed eHealth 2018(6):e12. Available at: https://journals.ukzn.ac.za/index.php/JISfTeH/article/v iew/505 accessed 31 January 2019.

24. Ho SH, Rerknimitr R, Kudo K, et al. Telemedicine for gastrointestinal endoscopy: The Endoscopic Club Econference in the Asia Pacific Region. Endosc Int Open 2017;5(4):E244-252. DOI: https://doi.org/10.1055/s-0043-102935. 